\title{
Arbuscular Mycorrhizal Fungi Enhance Sorghum Plant Growth under Nitrogen-Deficient Conditions through Activation of Nitrogen and Carbon Metabolism Enzymes
}

\author{
Anass Kchikich $^{1 \dagger}$, Reda Ben Mrid ${ }^{1,2 \dagger *}$, Imad Kabach ${ }^{1}$, Mohamed Nhiri ${ }^{1}$ and Redouane El Omari ${ }^{1,3}$ \\ ${ }^{1}$ Laboratory of Biochemistry and Molecular Genetics, Faculty of Science and Technology of Tangier, Abdelmalek Essaâdi \\ University, BP 416, 90000 Tangier, Morocco \\ ${ }^{2}$ AgroBioSciences Research Division, Mohammed VI Polytechnic University, Ben Guerir 43150, Morocco \\ ${ }^{3}$ Higher School of Technology (EST) Sidi Bennour, Chouaib Doukkali University, El Jadida, Morocco \\ *For correspondence: reda.benmrid@um6p.ma \\ ${ }^{\dagger}$ Contributed equally to this work and are co-first authors \\ Received 03 February 2020; Accepted 01 May 2021; Published 10 July 2021
}

\begin{abstract}
Nitrogen $(\mathrm{N})$, one of the most important elements for plant growth, is needed by plants in large quantities. However, this nutrient has limited supply in the soil. Arbuscular mycorrhizal fungi (AMF) are known for their ability to form symbiotic association with plants and transfer the mineral nutrients to the host plants. To validate this hypothesis on sorghum plants, three ecotypes of this cereal (3p4, 3p9 and 4p11) were cultivated with and without AMF under low nitrogen concentration (0.5 $\mathrm{mM} \mathrm{\textrm {NH } _ { 4 }}{ }^{+}$). Growth parameters were determined and key enzymes responsible for nitrogen and carbon metabolisms such as glutamine synthetase (GS), glutamate dehydrogenase (GDH), phosphoenolpyruvate carboxylase (PEPC), isocitrate dehydrogenase $(\mathrm{ICDH})$, malate dehydrogenase $(\mathrm{MDH})$ and asparate aminotransferase (AAT) were measured. For the three sorghum ecotypes, mycorrhizal plants showed a higher plant growth compared to the control plants. The biochemical parameters revealed a significant increase in the nitrogen assimilatory enzymes; GS and GDH in the leaves and roots of mycorrhizal plants. Furthermore, mycorrhizal fungi also appear to have a significant effect on carbon assimilatory enzymes. These enzymes are known to have a cardinal role in the provision of carbon skeletons essential for the assimilation of ammonium and thus, amino acids synthesis. Our study indicates clearly that AMF can be an efficient way to optimize nitrogen uptake and/or assimilation by plants and thus improve the crop yields with lower amount of nitrogen fertilizers. (C) 2021 Friends Science Publishers
\end{abstract}

Keywords: Arbuscular mycorrhizal fungi; Carbon metabolism; Enzyme activities; Nitrogen metabolism; Sorghum bicolor

\section{Introduction}

Appropriate fertilization is a necessity to reach both high yields and quality of crops. Nitrogen $(\mathrm{N})$ is required by plants in large quantities. However, in soil, this element is generally below the levels needed by crops for their optimal growth, the improvement of nitrogen use efficiency, particularly in cereals, is a major goal of crop refinement. Such improved crops would make better use of the nitrogen fertilizer supplied; they would also produce higher yields with better protein content (Yang et al. 2012).

Nitrogen is absorbed by plants mainly as nitrate $\left(\mathrm{NO}_{3}{ }^{-}\right)$ or ammonium $\left(\mathrm{NH}_{4}^{+}\right)$. In many plants, most of the nitrate absorbed by the roots is transported to the shoot ( $\mathrm{Xu}$ et al. 2012), where it is reduced first to nitrite $\left(\mathrm{NO}_{2}{ }^{-}\right)$by the enzyme nitrate reductase (NR) and then to $\mathrm{NH}_{4}{ }^{+}$by nitrite reductase (NiR). As for ammonium, it is directly incorporated into amino acids by the enzymes glutamine synthetase (GS) and glutamate synthase (GOGAT) who plays a central role in nitrogen metabolism (Valadier et al. 2008).

During $\mathrm{N}$ assimilation, a significant amount of carbon (C) is required to provide $\mathrm{C}$ skeleton, including 2oxoglutarate (2-OG) and oxaloacetate (OAA) used as amino group acceptors (Nunes-Nesi et al. 2010). Several enzymes, such PEPC, NADP-ICDH and NAD-MDH could lead to the synthesis of 2-OG (Rademacher et al. 2002; Popov et al. 2010). Ammonium assimilation in plants occurs principally via the GS/GOGAT cycle. Nevertheless, when $\mathrm{NH}_{4}{ }^{+}$is the sole $\mathrm{N}$ source, it could be assimilated through another metabolic pathway (Sarasketa et al. 2014). Indeed, when $\mathrm{NH}_{4}{ }^{+}$is the unique source of $\mathrm{N}, \mathrm{GDH}$ were reported to have a primordial role in $\mathrm{NH}_{4}{ }^{+}$assimilation, $\mathrm{GDH}$ uses $\mathrm{NH}_{4}^{+}$and 2-oxoglutarate to produce glutamate (Skopelitis et al. 2006; Setién et al. 2013).

To cite this paper: Kchikich A, RB Mrid, I Kabach, M Nhiri, RE Omari (2021). Arbuscular mycorrhizal fungi enhance sorghum plant growth under nitrogendeficient conditions through activation of nitrogen and carbon metabolism enzymes. Intl J Agric Biol 26:201-208 
Arbuscular mycorrhizal fungi (AMF) are soil borne microorganisms known for their ability to form symbiotic associations with different plant species. Their importance lies in the fact that they increase access to growth-limiting resources by the association of their hyphae to plant roots (Cobb et al. 2016). AMF are able to transfer inorganic $\mathrm{N}$ to the host plants (Hodge and Fitter 2010). They can also increase the use of different forms of $\mathrm{N}$ by plants and have been found to absorb this element directly and to transfer it to the roots of host plant (Govindarajulu et al. 2005). Nitrogen assimilated into glutamate and glutamine could be converted to other amino acids, through the enzyme activities of aminotransferase such as AAT, responsible for the formation of aspartate (Torre et al. 2014).

Sorghum bicolor $\left(\mathrm{L}\right.$.) is the $5^{\text {th }}$ most important cereal crop in the world. It is a drought tolerant cereal crop grown in the semiarid tropics of the world. Sorghum could be used as animal feed as it can be used as human food (Prakasham et al. 2014). In previous study we have shown that arbuscular mycorrhizal fungi lead to increase in shoots length and biomass in sorghum plants by the enhancement nutrient uptake provided to plants (Kchikich et al. 2021). AMF can also increase the use of different forms of $\mathrm{N}$ by absorption of this element directly and transfer it to the roots (Govindarajulu et al. 2005). Therefore, the aim of this study was to investigate effects of arbuscular mycorrhizal fungi on (i) parameters of growth and chlorophyll content (ii) activities of other enzymes involved in carbon and nitrogen metabolisms such as GS, GDH, ICDH, AAT, PEPC and $\mathrm{MDH}$ in roots and shoots of three Moroccan sorghum ecotypes (3p4, 3p9 and 4p11) under nitrogen-limiting conditions. Our overall objective was to determine the possible basis for the response of the mycorrhizal sorghum plants to $\mathrm{N}$ deficiency.

\section{Materials and Methods}

\section{Plant material and growth}

Sorghum seeds were sterilized using $5 \%$ of $\mathrm{NaOCl}$ for about $15 \mathrm{~min}$ and then washed with distilled water. Plants were cultivated in $18 \mathrm{~cm}$ plastic pots $\left(3000 \mathrm{~cm}^{3}\right)$ containing vermiculite as substrate. Twenty seeds per pot of each ecotype were planted. After one week, the plants were thinned to 15 per pot. The plants were grown under controlled conditions at $28^{\circ} \mathrm{C}$ day $/ 21-22^{\circ} \mathrm{C}$ night and a photoperiod of 16/8 h (light/dark). Three ecotypes were cultivated in the same conditions. Before sowing, vermiculite was mixed with the AMF (Glomus intraradices). Control plants were cultured without AMF. Nitrogen treatment in the form of ammonium sulphate $\left(\left(\mathrm{NH}_{4}\right)_{2} \mathrm{SO}_{4}\right)$ was provided at $0.5 \mathrm{~m} M$. Nitrogen supply was added after one week from the start of the experiment. The shoots and roots were harvested from 5-week-old plants and stored at $-80^{\circ} \mathrm{C}$ until use. The experiment was repeated three times $(n=3)$ under the same conditions.
Extraction and assay of GS, GDH, NADH-MDH and AAT

Frozen samples were used for extraction by the method described previously (Mrid et al. 2018); the leaves and roots were homogenized in $50 \mathrm{~m} M$ ice-cold phosphate buffer $(\mathrm{pH}$ 7.6) containing $14 \mathrm{~m} M \quad \beta$-mercaptoethanol, $1 \mathrm{~m} M$ Ethylenedia-minetetraacetic acid (EDTA), $1 \mathrm{~m} M$ phenylmethylsulfonyl fluoride (PMSF), 9.4 $\mu M$ leupeptin, and $10 \%(\mathrm{w} / \mathrm{v})$ glycerol. Then the solution was centrifuged at $12,000 \mathrm{~g}$ for $20 \mathrm{~min}$ and the supernatant was used for determination of enzyme activities. All procedures were performed at $0-4^{\circ} \mathrm{C}$.

The GR activity was measured using the transferase assay as described by Shapiro and Stadtman (1970) with some modifications as reported by Mrid et al. (2016). The assay mixture consisted of $90 \mathrm{mM}$ imidazole- $\mathrm{HCl}(\mathrm{pH} 7.0)$, $120 \mathrm{~m} M$ L-glutamine, $3 \mathrm{~m} M \mathrm{MnCl}_{2}, 0.4 \mathrm{~m} M$ ADP, $20 \mathrm{~m} M$

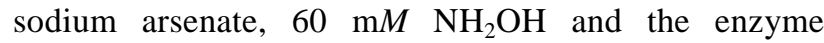
solution in a final volume of $2.25 \mathrm{~mL}$. The L-glutamine was omitted in the blank test. The reaction was started by adding $\mathrm{NH}_{2} \mathrm{OH}$ (prepared freshly, and neutralized to pH 7.0 with $\mathrm{NaOH}$ ) and incubated at $37^{\circ} \mathrm{C}$. The reaction was stopped by adding $0.75 \mathrm{~mL}$ of a mixture (1:1:1) of $10 \%$ $\mathrm{FeCl}_{3} \cdot 6 \mathrm{H}_{2} \mathrm{O}$ (in $0.2 \mathrm{~N} \mathrm{HCl}$ ), 24\% TCA and $5 \% \mathrm{HCl}$ after 15 min. The appearance of $\gamma$-glutamyl hydroxamate was measured at $540 \mathrm{~nm}$.

The GDH activity was measured in the aminating direction, as described by Sarasketa et al. (2014). The activity was performed in the amination direction at $30^{\circ} \mathrm{C}$ in reaction buffer containing $100 \mathrm{mM}$ Tris- $\mathrm{HCl}(\mathrm{pH}$ 8), $1 \mathrm{~m} M \mathrm{CaCl}_{2}, 13 \mathrm{~m} M \alpha$-ketoglutarate, $50 \mathrm{~m} M\left(\mathrm{NH}_{4}\right)_{2} \mathrm{SO}_{4}$ and $0.25 \mathrm{~m} M \mathrm{NADH}$. Kinetic activity was determined spectrophotometrically by monitoring NADH at $340 \mathrm{~nm}$. The activity of $\mathrm{NAD}^{+}$malate dehydrogenase was assayed by monitoring NADH at $340 \mathrm{~nm}$. The reaction buffer contained $50 \mathrm{~m} M$ potassium phosphate buffer $(\mathrm{pH}$ 7.5), $1 \mathrm{~m} M$ oxaloacetic acid, $0.25 \mathrm{~m} M \mathrm{NADH}$ and the enzyme solution.

NADH-MDH activity was determined according to the method of Setién et al. (2014). The MDH activity was measured by oxidation of NADH and the reduction kinetics of $\mathrm{NAD}^{+}$were monitored spectrophotometrically over a period of 3 min at $340 \mathrm{~nm}$. The reaction buffer containing $100 \mathrm{~m} M$ Hepes-KOH (pH 7.5), $5 \mathrm{mM} \mathrm{MgCl}_{2}, 2 \mathrm{~m} M$ oxaloacetate and $0.2 \mathrm{~m} M$ NADH was used. The reactions started by addition of the extracts.

AAT activity was measured following the protocol of Rej (1979) with some modifications (Mrid et al. 2018). The activity was measured by coupling oxalacetate production with malate dehydrogenase and $\mathrm{NADH}$ and measuring the decrease in absorbance at $340 \mathrm{~nm}$ at $30^{\circ} \mathrm{C}$ in a $1 \mathrm{~mL}$ assay mixture containing: Tris- $\mathrm{HCl} 50 \mathrm{mM}, \mathrm{pH} 7.8$, L-aspartate $50 \mathrm{~m} M$, 2-oxoglutarate $10 \mathrm{~m} M$, NADH $0.1 \mathrm{~m} M, 2 \mathrm{U}$ of $\mathrm{MDH}$ and $20 \mu \mathrm{L}$ of roots extract. The reaction was initiated by adding 2-oxoglutarate. 


\section{Extraction and assay of PEPC and NADP ${ }^{+}-\mathrm{ICDH}$}

Frozen samples were used for extraction by the method described previously (Mrid et al. 2018). The supernatant was saturated $(60 \%)$ with solid ammonium sulphate for $30 \mathrm{~min}$. The saturated supernatant was centrifuged at $12,000 \mathrm{~g}$ for $20 \mathrm{~min}$ and the resulting pellet was resuspended in the extraction buffer and used for enzyme assays.

The PEPC activity was carried out following the method of Omari et al. (2016). The activity was assayed by coupling to NAD-malic dehydrogenase (MDH) and monitoring NADH oxidation at $340 \mathrm{~nm}$ spectrophotometrically in a $1 \mathrm{~mL}$ assay mixture containing $100 \mathrm{~m} M$ Hepes-KOH (pH 7.3), $5 \mathrm{mM} \mathrm{MgCl}_{2}, 0.2 \mathrm{~m} M$ $\mathrm{NADH}, 5 \mathrm{U}$ of MDH, $2.5 \mathrm{~m} M$ PEP (for roots $1 \mathrm{~m} M$ ), $5 \mathrm{~m} M$ $\mathrm{NaHCO}_{3}$ and leaves or roots extract. One unit of PEPC is the amount of enzyme extract which catalyzes the transformation of $1 \mu \mathrm{mol}$ substrate per minute at $30^{\circ} \mathrm{C}$.

$\mathrm{NADP}^{+}$-ICDH activity monitored as reported by Magalhaes and Huber (1991) with some modifications. The ICDH activity was measured spectrophotometrically by monitoring the oxidation of NADH at $340 \mathrm{~nm}$ for $5 \mathrm{~min}$. The assay mixture contains: $50 \mathrm{~m} M$ potassium phosphate buffer (pH 7.5), $1 \mathrm{~m} M \mathrm{NADP}^{+}, 1 \mathrm{~m} M \mathrm{MnCl}_{2}$ and $4 \mathrm{~m} M$ isocitrate.

\section{Estimation of protein}

Protein content was measured following the method of Bradford (1976). Bovine Serum Albumin (BSA) was used as a protein standard.

\section{Statistical Analysis}

Statistical analyses were conducted using the software PASW statistics (v. 18). One-way ANOVA analysis and Tukey's post-hoc tests were conducted to determine significant differences between means $(P<0.05)$.

\section{Results}

\section{Effect of AMF on growth parameters}

To evaluate the effect of AMF on the three sorghum ecotypes (3p4, 5p3 and 4p11) under nitrogen deficiency, some growth parameters as length and fresh weights were measured. The Table 1 showed that AMF contribute significantly to the growth of the three sorghum ecotypes (5p3, 3p9 and 4p11). In fact, the shoot length of the mycorrhizal plants increased by 36,45 and $46 \%$ for the $3 \mathrm{p} 4$, 3 p9 and 4p11 ecotypes respectively as compared to control plants. The increase in the fresh weight was about 55, 35 and $44 \%$ for these ecotypes compared to the nonmycorrhizal plants.
Table 1: Influence of AM fungal colonization on length and fresh weight $(\mathrm{FW})$ in shoots of three sorghum ecotypes growing at $\mathrm{N}$ deficiency condition. (-) Non-inoculated (+) inoculated by Glomus intraradices

\begin{tabular}{lll}
\hline Ecotype & Shoot length $(\mathrm{cm})$ & Shoot fresh weight $(\mathrm{g})$ \\
\hline $3 \mathrm{p} 4+$ & $28.5 \pm 1.29 \mathrm{a}$ & $0.28 \pm 0.059 \mathrm{a}$ \\
$3 \mathrm{p} 4^{-}$ & $21.00 \pm 2.94 \mathrm{bd}$ & $0.18 \pm 0.031 \mathrm{ab}$ \\
$3 \mathrm{p} 9+$ & $26.88 \pm 0.85 \mathrm{c}$ & $0.23 \pm 0.028 \mathrm{bc}$ \\
$3 \mathrm{p} 9^{-}$ & $18.50 \pm 1.29 \mathrm{ce}$ & $0.17 \pm 0.021 \mathrm{c}$ \\
4p11+ & $23.00 \pm 1.83 \mathrm{~d}$ & $0.18 \pm 0.025 \mathrm{ac}$ \\
4p11 & $15.75 \pm 2.50 \mathrm{c}$ & $0.10 \pm 0.009 \mathrm{bc}$ \\
\hline \multicolumn{2}{l}{ Each value represents the mean of three independent observations with S.D. Different } \\
letters indicate significant difference between treatments at 5\% level
\end{tabular}

\section{Effect of AMF on chlorophyll content in leaves of the sorghum plant}

Results shown in Fig. 1 indicates that under the N-deficient condition (-N), the total chlorophyll content increased significantly in the mycorrhizal plants. However, the effect of this mycorrhization on the chlorophyll content was not the same. In fact, the 4p11 ecotype was more influenced by the mycorrhization and showed an increase by $58 \%$ in the total chlorophyll content, followed by the 3p4 ecotype $(25 \%)$ and then the $3 \mathrm{p} 9$ ecotype $(16 \%)$.

\section{Effect of AMF on GS and GDH activities in the shoots and roots of sorghum plants}

Because the nitrogen source used was ammonium, it was interesting to analyze the enzyme activities of the ammonium assimilatory enzymes; GS and GDH. The Fig. 2 indicates that, regardless of the ecotype, a significant increase in GS activity was noted in both shoots and roots of sorghum in the presence of AMF compared to plants without mycorrhization. In fact, GS activity increased by almost twice for the 3p4 and 3p9 ecotypes and increased by more than twice for the $4 \mathrm{p} 11$ ecotype in the shoots of mycorrhizal plants. In roots, GS activity was mainly affected in the $4 \mathrm{p} 11$ ecotype followed by the $3 \mathrm{p} 9$ ecotype and finally the $3 \mathrm{p} 4$ ecotype.

The Fig. 3 indicates that the activity of GDH varied from $0.09 \mu$ mol NADH.min ${ }^{-1}$. $\mathrm{g}^{-1} \mathrm{FW}$ to $0.15 \mu \mathrm{mol}$ NADH.min ${ }^{-1} \cdot \mathrm{g}^{-1} \mathrm{FW}$ for the shoots of the three ecotypes and from $0.09 \mu \mathrm{mol} \mathrm{NADH} \cdot \mathrm{min}^{-1} \cdot \mathrm{g}^{-1} \mathrm{FW}$ at $0.20 \mathrm{~m} M \mu \mathrm{mol}$ NADH.min ${ }^{-1} \cdot \mathrm{g}^{-1} \mathrm{FW}$ for the roots of the three ecotypes. In the presence of AMF, GDH activity has significantly increased in the roots and shoots of sorghum. Indeed, the activity of GDH increased by 18, 54 and $63 \%$ in the shoots, and by 53,32 and 58 in the roots in the ecotypes $3 \mathrm{p} 4,3 \mathrm{p} 9$ and 4 p11, respectively.

\section{Effect of AMF on PEPC and MDH activities in the sorghum shoots and roots}

Fig. 4 and 5 showed the activities of PEPC and MDH in shoots and roots of the three sorghum ecotypes grown with or without AMF. Regardless of the ecotype, the increase of 


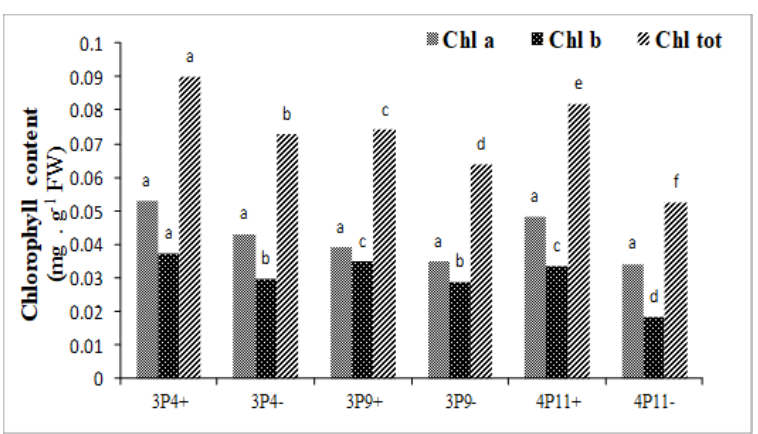

Fig. 1: Influence of AM fungal colonization on chlorophyll content in leaves of three sorghum ecotypes growing at $\mathrm{N}$ deficiency condition. (-) Non-inoculated (+) inoculated by Glomus intraradices. Each value represents the mean of three independent observations with S.D. Different letters indicate significant difference between treatments at $5 \%$ level

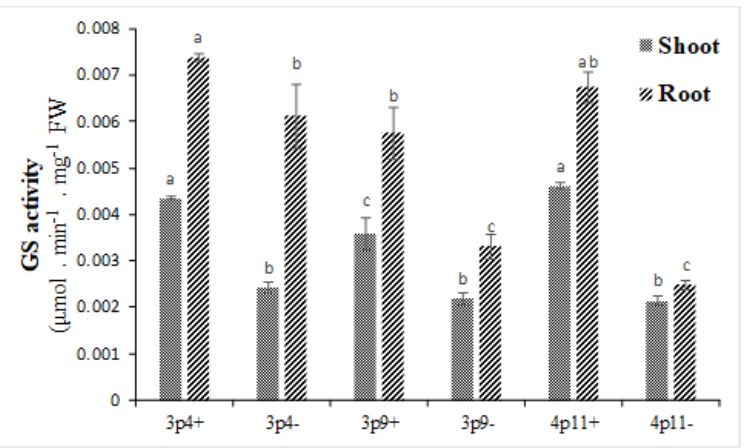

Fig. 2: Influence of AM fungal colonization on glutamine synthetase (GS) activity in shoots and roots of three sorghum ecotypes growing at $\mathrm{N}$ deficiency condition. (-) Non-inoculated (+) inoculated by Glomus intraradices. Each value represents the mean of three independent observations with S.D. Different letters indicate significant difference between treatments at $5 \%$ level

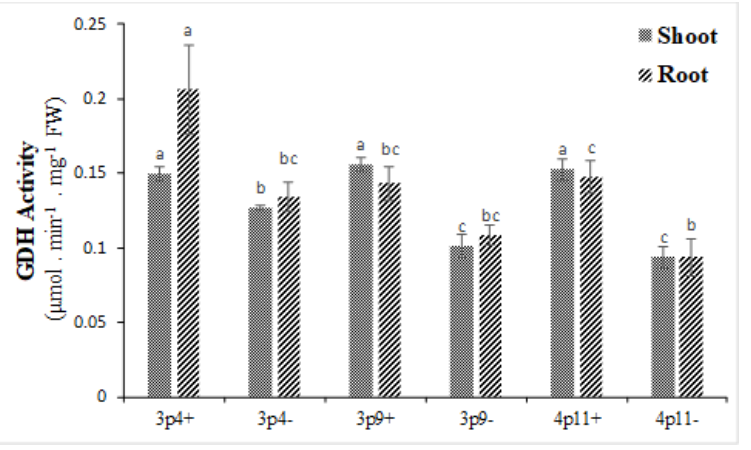

Fig. 3: Influence of AM fungal colonization on glutamate dehydrogenase (GDH) activity in shoots and roots of three sorghum ecotypes growing at $\mathrm{N}$ deficiency condition. (-) Noninoculated (+) inoculated by Glomus intraradices. Each value represents the mean of three independent observations with S.D. Different letters indicate significant difference between treatments at $5 \%$ level

the activities of these enzymes was significant. For PEPC, the increase of the activity was very remarkable, especially

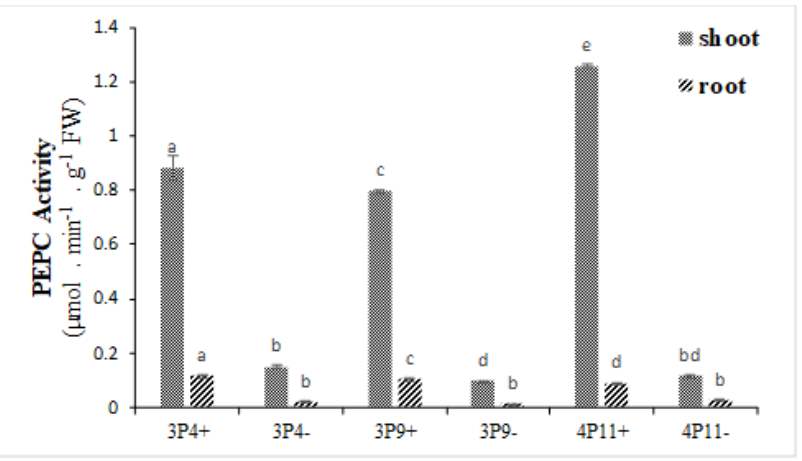

Fig. 4: Influence of AM fungal colonization on phosphoenolpyruvate carboxylase (PEPC) activity in shoots and roots of three sorghum ecotypes growing at $\mathrm{N}$ deficiency condition. (-) Non-inoculated (+) inoculated by Glomus intraradices. Each value represents the mean of three independent observations with S.D. Different letters indicate significant difference between treatments at $5 \%$ level

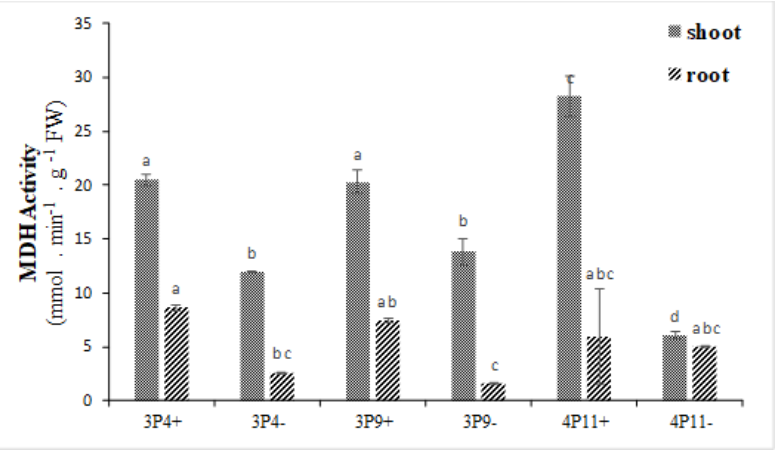

Fig. 5: Influence of AM fungal colonization on malate dehydrogenase $(\mathrm{MDH})$ activity in shoots and roots of three sorghum ecotypes growing at $\mathrm{N}$ deficiency condition. (-) Noninoculated $(+)$ inoculated by Glomus intraradices. Each value represents the mean of three independent observations with S.D. Different letters indicate significant difference between treatments at $5 \%$ level

in shoots. In fact, the PEPC activity in shoots increased 5fold for the $3 \mathrm{p} 4$ and $3 \mathrm{p} 9$ ecotypes, while for the $4 \mathrm{p} 11$ ecotype the increase of the activity was 6-fold compared to the control plants. The increase of the MDH activity was also significant. It should be noted here, that for both activities, shoots of the $4 \mathrm{p} 11$ ecotype was more influenced by the mycorrhization compared to the two other ecotypes.

\section{Effect of AMF on ICDH and AAT activities in the sorghum shoots and roots}

In our study, mycorrhizal ecotypes led to high ICDH activity compared to the control plants. In fact, this activity has almost doubled for the three ecotypes in roots and shoots; however, for the $4 \mathrm{p} 11$ ecotype the difference in the enzyme activity between the control plants and the mycorrhizal plants was the much higher (Fig. 6). 


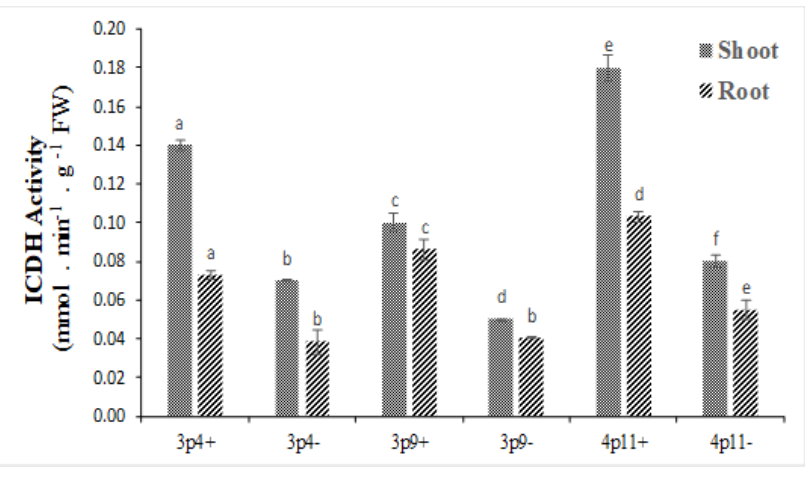

Fig. 6: Influence of AM fungal colonization on isocitrate dehydrogenase (ICDH) activity in shoots and roots of three sorghum ecotypes growing at $\mathrm{N}$ deficiency condition. (-) Noninoculated (+) inoculated by Glomus intraradices. Each value represents the mean of three independent observations with S.D. Different letters indicate significant difference between treatments at $5 \%$ level

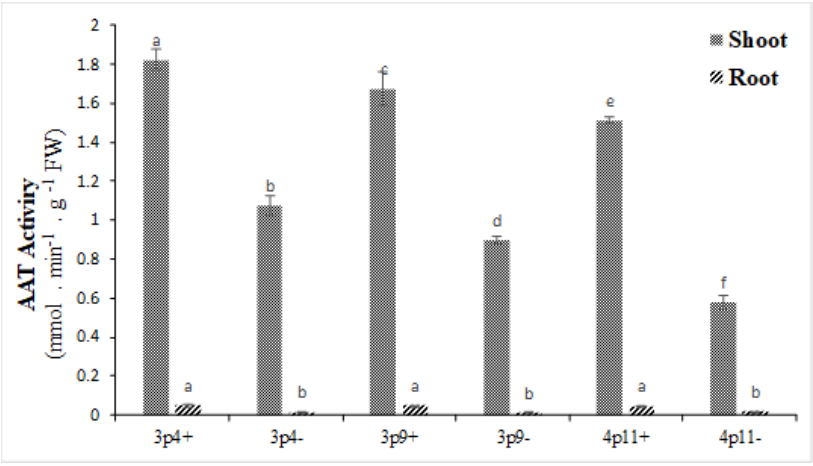

Fig. 7: Influence of AM fungal colonization on aspartate aminotransferase (AAT) activity in shoots and roots of three sorghum ecotypes growing at $\mathrm{N}$ deficiency condition. (-) Noninoculated (+) inoculated by Glomus intraradices. Each value represents the mean of three independent observations with S.D. Different letters indicate significant difference between treatments at $5 \%$ level

Concerning the AAT activity, Fig. 7 showed the same trend of increase between the mycorrhizal ecotypes and the control plants where a higher effect on the 4p11 ecotype was observed. For this activity, it has been noticed that the activity was more induced in the sorghum shoots compared to the roots (Fig. 7).

\section{Discussion}

Sorghum plants inoculated with Glomus intraradices showed increased growth, compared to non-mycorrhizal plants. As for sorghum, the effect of AMF on growth enhancement has been described in previous works using different fungal species in combination with strawberry cultivars (Varma and Schuepp 1994). Moreover, Marschner and Dell (1994) reported that the AMF has led in increase of the host plant growth primarily by increasing phosphorus uptake. Other studies have revealed a significant effect of AMF on root development of white clover by endogenous hormone balance. AMF in the soil, which are symbiotic to most terrestrial plants can also enhance plant growth and yield production through increasing the uptake of water and nutrients by the host plant (Wu et al. 2011; Shao et al. 2018).

Nitrogen is an essential constituent of chlorophyll. An adequate supply of $\mathrm{N}$ might result in high photosynthetic activity and vigorous vegetative growth (Kafle and Sharma 2015). Mitova et al. (2017) have found that the chlorophyll content in two varieties of lettuce was affected significantly by the mycorrhizal fungi inoculation, but much higher values were observed in one of these varieties compared to the other. The increase of the chlorophyll content by the mycorrhizal fungi inoculation might be due to the activated synthesis of free amino acids triggering the chain of chlorophyll biosynthesis (Smolov and Semenova 2008). Qin et al. (2017) reported that high chlorophyll content in mycorrhizal plants may be responsible for the increment in nutrients uptake such us $\mathrm{N}, \mathrm{P}$ and $\mathrm{Mg}$.

Nitrogen $(\mathrm{N})$ is among the most important macronutrients significantly affecting plant growth and yield production. Glutamine synthetase is one of the key enzymes responsible for the assimilation of inorganic $\mathrm{N}$. It catalyzes the formation of glutamine. This metabolite will provide $\mathrm{N}$ groups for the biosynthesis of all nitrogenous compounds of the plant. In the present study we observed increased activity of GS in roots and shoots of the sorghum plants under Arbuscular mycorrhizal (AM) fungus. Mitova et al. (2017) have obtained the same trend of changes regarding GS activity with a differential response between the different tested varieties of lettuce. In another study, three AMF (Glomus intraradices, G. etunicatum and G. mosseae) enhanced the GS activity in the roots of maize (Deng et al. 2009). According to these authors it has been indicated that AMF plays a significant role in $\mathrm{NH}_{4}{ }^{+}$ utilization of the host plants.

Among the enzymes having the capacity to catalyse the assimilation of $\mathrm{NH}_{4}{ }^{+}$into organic molecules, we can cite the glutamate dehydrogenase (GDH). In fact, it was reported that NADH-GDH may incorporate ammonium in glutamate under stress conditions (Skopelitis et al. 2006; MasclauxDaubresse et al. 2010; Setién et al. 2013; Omari and Nhiri 2015). Saito (1994) reported that increased GDH activity is associated with plant mycorrhization.

The enhanced activities of glutamine synthetase, and glutamine synthase in the roots and shoots of mycorrhizal corn indicate that the absorbed $\mathrm{NO}_{3}$ by $\mathrm{AM}$ hypha can be directly transferred to the root cells for further utilization and incorporation into the organic structures. Such enzymatic alterations can also enhance plant resistance to drought stress. This indicates that in addition to the direct effects of AM fungi on the alleviation of stresses such as drought, their indirect effect such as absorbing inorganic $\mathrm{N}$ 
can also contribute to the alleviation of stress. AM fungi are able to alter plant physiological and morphological properties in a way by which plant can handle the stress (Miransari 2011).

The increase of the enzymatic activities of GS and GDH in the roots and shoots of the three sorghum ecotypes indicates that ammonium might first be concentrated by $\mathrm{AMF}$ and then translocated to the root cells for use and incorporation into organic structures. The results found by Nakmee et al. (2016) confirm the results that we obtained. In fact, these authors revealed that the AMF significantly increased the percentage of $\mathrm{N}$ in shoots and the total $\mathrm{N}$ uptake in shoots and roots of sorghum. In another study conducted by Govindarajulu et al. (2005) using stable isotope labelling experiments reported that the inorganic $\mathrm{N}$ absorbed by the AMF outside the roots is metabolized to form amino acids. Amino acids are then translocated to the intraradical mycelium as arginine. Arginine is then transferred to the plant without carbon. Ammonia generated from arginine catabolism is translocated to the host via ammonia channels. These results could explain the increase of the enzymes GS/GDH activities in the plants.

To our knowledge, this is the first study aiming to determine the effect of plant mycorrhization on the carbon metabolism enzymes under $\mathrm{N}$ deficiency conditions in sorghum plant. In a study conducted by Hashem et al. (2015), the authors showed that the AMF can alleviate the decease of carbon assimilation-related enzyme activities, such as PEPC, induced by salt stress. In our study, the increase in the PEPC and MDH activities may be related to the increase in the $\mathrm{N}$ assimilation-related enzyme activities (GS and GDH). There are many reports of increased PEPC activity with $\mathrm{NH}^{4+}$ versus nitrogen nutrition although other works show that $\mathrm{NO}_{3}{ }^{-}$supply can stimulate PEPC activity (Champigny 1995). In fact, the accumulation of amino acids in the roots and leaves requires an adequate amount of keto acids, particularly the 2-oxoglutarate and oxaloacetate. These carbon skeletons originate from the tricarboxylic acid cycle (TCA). Both PEPC and MDH have been shown to fulfil a central role in the replenishment of the TCA. Thus, the increase in PEPC and MDH activities could be essential for the supply of carbon compounds required for the synthesis of amino acids and thus, proteins (Mrid et al. 2018). In the study conducted by Chen et al. (2017), the authors showed that mycorrhizal fungi of the genera Funneliformis, Claroideoglomus, Rhizophagus and Diversispora were responsible for an increase in the stomatal conductance and the intensity of $\mathrm{CO}_{2}$ assimilation in cucumber plants.

In the literature, isocitrate dehydrogenases and aspartate aminotransferases were reported to have a direct role in the furniture of key organic acids for the assimilation of ammonium (Hodges et al. 2003). It was stated that $95 \%$ of the total ICDH activity in green tobacco leaves was attributed to the cytosolic form of the ICDH (Gálvez et al. 1994) and that this enzyme is the predominant isoform in several plants (Fieuw et al. 1995; Gallardo et al. 1995; Palomo et al. 1998). It has been proposed that this cytosolic ICDH may play a major role in the production of 2 oxoglutarate for amino acid synthesis (Mrid et al. 2017). Boiffin et al. (1998) showed that the activity of $\mathrm{NADP}^{+}$ICDH increased in the roots of Eucaluptus globulus subsp. Bicostata during colonization by an ectomycorrhizal fungus.

Mycorrhizal fungi are able to enhance the uptake of $\mathrm{N}$ from $\mathrm{NH}_{4}^{+}$fertilizers and carrying it to their host plants (Ames et al. 1983; Johansen et al. 1993). Chambers et al. (1980) have shown that amides and amino acids, particularly; asparagine and aspartate could be higher in exudates from ammonium fed plants. We can suggest that the higher AAT activity in mycorrhizal plants can be correlated with its role in metabolizing glutamate, resulting from $\mathrm{NH}_{4}{ }^{+}$assimilation to aspartate that may be used for the biosynthesis of other amino acids (Forde and Lea 2007).

\section{Conclusion}

In present work, we showed also that AMF had a positive effect on plant growth. We showed also that the results of the growth parameters are in line with the results of the carbon and nitrogen metabolism enzyme activities. In fact, the role of these enzymes is strongly related to the synthesis of organic compounds required for nitrogen assimilation and thus amino acids and protein synthesis a process required for plant growth and development. These results could have an important socio-economic and ecological impact because they show a clear increase in the efficiency of nitrogen utilization for the mycorrhizal plants under low nitrogen inputs. This would save the costs associated with the input of nitrogen fertilizer and will also reduce any pollution related to its use.

\section{Author Contributions}

Anass Kchikich and Reda Ben Mrid conceived and designed the experiments; Anass Kchikich, Imad Kabach, and Reda Ben Mrid performed the experiments; Anass Kchikich, Imad Kabach, Reda Ben Mrid, Mohamed Nhiri, and Redouane El Omari analyzed the data and prepared the document; Mohamed Nhiri and Redouane El Omari, supervised the work.

\section{Conflict of Interest}

There are no conflicts to declare.

\section{Data Availability}

The data presented in this study are available on request from the corresponding author.

\section{Ethics Approval}

There are no researches conducted on animals or humans. 


\section{References}

Ames RN, CPP Reid, Lk Porter, C Cambardella (1983). Hyphal uptake and transport of nitrogen from ${ }^{15} \mathrm{~N}$-labelled sources by Glomus mosseae, a vesicular-arbuscular mycorrhizal fungus. New Phytol 95:381-396

Boiffin V, M Hodges, S Galvez, R Balestrini, P Bonfante, P Gadal, F Martin (1998). Eucalypt NADP-dependent Isocitrate dehydrogenase cDNA cloning and expression in Ectomycorrhizae. Plant Physiol 117:939-948

Bradford MM (1976). A rapid and sensitive method for the quantification of microgram quantities of protein utilizing the principle of protein-dye binding. Anal Biochem 72:248-254

Chambers CA, SE Smith, FA Smith (1980). Effects of ammonium and nitrate ions on mycorrhizal infection, nodulation and growth of Trifolium subterraneum. New Phytol 85:47-62

Champigny ML (1995). Integration of photosynthetic carbon and nitrogen metabolism in higher plants. Photosynth Res 46:117-127

Chen S, H Zhao, C Zou, Y Li, Y Chen, Z Wang, Y Jiang, P Zhao, M Wang, GJ Ahammed (2017). Combined inoculation with multiple arbuscular mycorrhizal fungi improves growth, nutrient uptake and photosynthesis in cucumber seedling. Front Microbiol 8; Article 2516

Cobb AB, GWT Wilson, CL Goad, SR Bean, RC Kaufman, TJ Herald, JD Wilson (2016). The role of arbuscular mycorrhizal fungi in grain production and nutrition of sorghum genotypes: Enhancing sustainability through plant-microbial partnership. Agric Ecosyst Environ 233:432-440

Deng Y, H Shen, W Luo, T Guo (2009). Effects of AMF on key enzymes of nitrogen assimilation in maize under different ammonium to nitrate ratios. Plant Nutr Fert Sci 15:1380-1385

Fieuw S, B Müller-Rober, S Cálvez, L Willmitzer (1995). Cloning and expression analysis of the cytosolic $\mathrm{NADP}^{+}$- dependent isocitrate dehydrogenase from potato. Plant Physiol 107:905-913

Forde BG, PJ Lea (2007). Glutamate in plants: Metabolism, regulation and signalling. J Exp Bot 58:2339-2358

Gallardo F, M Miginiac-Maslow, RS Sangwan, P Decottignies, E Keryer, F Dubois, E Bismuth, S Galvez, B Sangwan-Norreel, P Gadal, C Crétin (1995). Monocotyledonous $\mathrm{C}_{4} \mathrm{NADP}^{+}$-malate dehydrogenase is efficiently synthesized, targeted to chloroplasts and processed to an active form in transgenic plants of the $\mathrm{C}_{3}$ dicotyledon tobacco Planta 197:324-332

Gálvez S, E Bismuth, C Sarda, P Gadal (1994). Purification and characterization of chloroplast NADP-isocitrate dehydrogenase from mixotrophic tobacco cells. Comparison with the cytosolic isoenzyme. Plant Physiol 105:593-600

Govindarajulu M, PE Pfeffer, J Abubaker, DD Douds, JW Allen, H Bucking, PJ Lammers, Y Shachar-Hill (2005). Nitrogen transfer in the arbuscular mycorrhizal symbiosis. Nature 435:819-823

Hashem A, EF AbdAllah, AA Alqarawi, A Aldubise, DE Gamberdieva (2015). Arbuscular mycorrhizal fungi enhances salinity tolerance of Panicum turgidum Forssk by altering photosynthetic and antioxidant pathways. J Plant Interact 10:230-242

Hodge A, AH Fitter (2010). Substantial nitrogen acquisition by arbuscular mycorrhizal fungi from organic material has implications for $\mathrm{N}$ cycling. Proc Natl Acad Sci 107:13754-13759

Hodges M, V Flesch, S Gálvez, E Bismuth (2003). Higher plant NADP ${ }_{-}$ dependent isocitrate dehydrogenases, ammonium assimilation and NADPH production. Plant Physiol Biochem 41:577-585

Johansen A, I Jakobsen, ES Jensen (1993). Hyphal transport by a vesiculararbuscular mycorrhizal fungus of $\mathrm{N}$ applied to the soil as ammonium or nitrate. Biol Fert Soils 16:66-70

Kafle S, PK Sharma (2015). Effect of integration of organic and inorganic sources of nitrogen on growth, yield and nutrient uptake by maize (Zea mays L.). Intl J Appl Sci Biotechnol 3:31-37

Kchikich A, RB Mrid, I Kabach, RE Omari, Y Bouargalne, A Amakran, M Nhiri (2021). Effect of mycorrhization on growth and enzymes involved in carbon/nitrogen interaction in sorghum plants. Res $J$ Biotech 16:121-126
Magalhaes JR, DM Huber (1991). Response of ammonium assimilating enzymes to nitrogen form treatments in different plant species. $J$ Plant Nutr 14:175-185

Marschner H, B Dell (1994). Nutrient uptake in mycorrhizal symbiosis. Plant Soil 159:89-102

Masclaux-Daubresse C, F Daniel-Vedele, J Dechorgnat, F Chardon, L Gaufichon, A Suzuki (2010). Nitrogen uptake, assimilation and remobilization in plants: Challenges for sustainable and productive agriculture. Ann Bot 105:1141-1157

Miransari M (2011). Arbuscular mycorrhizal fungi and nitrogen uptake. Arch Microbiol 193:77-81

Mitova I, L Nenova, I Stancheva, M Geneva, M Hristozkova, J Mincheva (2017). Lettuce response to nitrogen fertilizers and root mycorrhization. Bulg J Agric Sci 23:260-264

Mrid RB, Y Bouargalne, RE Omari, NE Mourabit, M Nhiri (2018), Activities of carbon and nitrogen metabolism enzymes of sorghum (Sorghum bicolor L. Moench) during seed development. J Crop Sci Biotechnol 21:283-289

Mrid RB, RE Omari, Y Bouargalne, NE Mourabit, M Nhiri (2017). Activities of carbon and nitrogen metabolism enzymes during germinating sorghum seeds and early seedlings growth. Cer Res Commun 45:587-597

Mrid RB, RE Omari, M Nhiri (2016). Effect of nitrogen source and concentration on growth and activity of nitrogen assimilation enzymes in roots of a Moroccan sorghum ecotype. Plant 4:71-77

Nakmee PS, S Techapinyawat, S Ngamprasit (2016). Comparative potentials of native arbuscular mycorrhizal fungi to improve nutrient uptake and biomass of Sorghum bicolor L. Agric Nat Resour 50:173-178

Nunes-Nesi A, AR Fernie, M Stitt (2010). Metabolic and signaling aspects underpinning the regulation of plant carbon nitrogen interactions. Mol Plant 3:973-996

Omari RE, M Nhiri (2015). Effect of high levels of ammonium or nitrate on growth and nitrogen metabolism in roots and leaves of sorghum (Sorghum sudangrass) plants. Amer Euras J Agric Environ Sci 15:1860-1867

Omari RE, RB Mrid, F Chibi, M Nhiri (2016). Involvement of phosphoenolpyruvate carboxylase and antioxydants enzymes in nitrogen nutrition tolerance in Sorghum bicolor plants. Russ J Plant Physiol 63:719-726

Palomo J, F Gallardo, MF Suarez, FM Canovas (1998). Purification and characterization of NADP-linked isocitrate dehydrogenase from Scots pine. Evidence for different physiological roles of the enzyme in primary development. Plant Physiol 118:617-626

Popov VN, AT Eprintsev, DN Fedorin, AU Igamberdiev (2010). Succinate dehydrogenase in Arabidopsis thaliana is regulated by light via phytochrome A. FEBS Lett 584:199-202

Prakasham RS, D Nagaiah, KS Vinutha, A Uma, T Chiranjeevi, AV Umakanth, PS Rao, N Yan (2014). Sorghum biomass: A novel renewablecarbon source for industrial bioproducts. Biofuels 5:159-174

Qin, YQ Shang, Y Zhang, P Li, Y Chai (2017). Bacillus amyloliquefaciens L-S60 reforms the rhizosphere bacterial community and improves growth conditions in cucumber plug seedling. Front Microbiol 8; Article 2620

Rademacher T, RE Häusler, HJ Hirsch, L Zhang, V Lipka, D Weier, F Kreuzaler, C Peterhänsel (2002). An engineered phosphoenolpyruvate carboxylase redirects carbon and nitrogen flow in transgenic potato plants. Plant J 32:25-39

Rej R (1979). Measurement of aspartate aminotransferase activity: Effects of oxamate. Clin Chem 25:555-559

Saito M (1994). Enzyme activities of the internal hyphae and germinated spores of an arbuscular mycorrhizal fungus, Gigaspora margarita Becker \& Hall. New Phytol 129:425-431

Sarasketa A, MB González-Moro, C González-Murua, D Marino (2014). Exploring ammonium tolerance in a large panel of Arabidopsi thaliana natural accessions. J Exp Bot 65:6023-6033

Setién I, I Vega-Mas, N Celestino, ME Calleja-Cervantes, C GonzálezMurua, JM Estavillo, MB González-Moro (2014). Root phosphoenolpyruvate carboxylase and NAD-malic enzymes activity increase the ammonium-assimilating capacity in tomato. J Plant Physiol 171:49-63 
Kchikich et al. / Intl J Agric Biol, Vol 26, No 2, 2021

Setién I, T Fuertes-Mendizabal, A Gonzalez, PM Aparicio-Tejo, C Gonzalez-Murua, MB Gonzalez-Moro, JM Estavillo (2013). High irradiance improves ammonium tolerance in wheat plants by increasing $\mathrm{N}$ assimilation. J Plant Physiol 170:758-771

Shao YD, DJ Zhang, XC HU, QS WU, CJ Jiang, TJ XIA, XB GAO, K KUČA (2018). Mycorrhiza-induced changes in root growth and nutrient absorption of tea plants. Plant Soil Environ 64:283-289

Shapiro BM, ER Stadtman (1970). Glutamine synthetase (Escherichia coli). Meth Enzymol 17:910-922

Skopelitis DS, NV Paranychianaki, KA Paschalidis, ED Pliakonis, ID Delis, DI Yakoumakis, A Kouvarakis, AK Papadakis, EG Stephanou, KA Roubelakis-Angelakis (2006). Abiotic stress generates ROS that signal expression of anionic glutamate dehydrogenases to form glutamate for proline synthesis in tobacco and grapevine. Plant Cell 18:2767-2781

Smolov AP, GA Semenova (2008). Effect of ammonium concentration on protein and chlorophyll contents and the number of ribosomes in the cells of soybean mixotrophic callus. Russ J Plant Physiol 55:359-364
Torre F, RA Cañas, MB Pascual, C Avila, FM Cánovas (2014). Plastidic aspartate aminotransferases and the biosynthesis of essential amino acids in plants. $J$ Exp Bot 65:5527-5534

Valadier MH, A Yoshida, O Grandjean, H Morin, J Kronenberger, S Boutet, A Raballand, T Hase, T Yoneyama, A Suzuki (2008). Implication of the glutamine synthetase/glutamate synthase pathway in conditioning the amino acid metabolism in bundle sheath and mesophyll cells of maize leaves. FEBS J 275:3193-3206

Varma A, H Schuepp (1994). Infectivity and effectiveness of Glomus intraradices on micropropagated plants. Mycorrhiza 5:29-37

Wu QS, YN Zou, XH He, P Luo (2011). Arbuscular mycorrhizal fungi can alter some root characters and physiological status in trifoliale orange (Poncirus trifoliata L.) seedlings. Plant Growth Regul 65:273-278

Xu GH, XR Fan, AJ Miller (2012). Plant nitrogen assimilation and use efficiency. Annu Rev Plant Biol 63:153-182

Yang X, X Wang, M Wei, S Hikosaka, E Goto (2012). Changes of glutamine and asparagine content in cucumber seedlings in response to nitrate stress. Intl J Plant Prod 5:1-8 